\title{
CRESCIMENTO DE MUDAS DE Prunus sellowii Koehne EM RESPOSTA A ADUBAÇÕES COM NPK E PÓ DE BASALTO
}

\author{
Juliane Garcia Knapik*, Alessandro Camargo Angelo** \\ *Eng ${ }^{\mathrm{a}}$. Florestal, M.Sc. - juknapik@yahoo.com.br \\ **Eng. Florestal, Dr., Depto. de Ciências Florestais, UFPR - alessandro.angelo@ufpr.br \\ Recebido para publicação: 01/11/2005 - Aceito para publicação: 19/10/2006
}

\begin{abstract}
Resumo
Este trabalho objetivou comparar o crescimento de mudas de Prunus sellowii Koehne (pessegueirobravo), submetidas a adubações convencionais e, como alternativa, ao pó de basalto. O experimento foi instalado em janeiro de 2004 no viveiro da Embrapa Florestas (Colombo/PR), utilizando-se tubetes médios $\left(100 \mathrm{~cm}^{3}\right)$ e substrato comercial à base de casca de Pinus sp. e vermiculita. O delineamento foi em blocos ao acaso, nos seguintes tratamentos: sem adubação; adubação mineral NPK; adubação mineral NPK com micronutrientes; e pó de basalto. As variáveis analisadas foram altura, diâmetro de colo, biomassa seca (aérea e radicular) e análise de nutrientes foliares. Os resultados mostraram o melhor crescimento das mudas quando adubadas com NPK, acrescida ou não com micronutrientes. Mudas produzidas com pó de basalto não obtiveram crescimento similar àquelas que receberam adubação convencional, no entanto, neste tratamento foram observados os maiores valores de N, P, Ca, Mg, B, Fe e Mn nas folhas.
\end{abstract}

Palavras-chave: Pessegueiro-bravo; viveiro; adubação.

\begin{abstract}
Growth of Prunus sellowii Koehne seedlings in response to NPK fertilizers and basalt dust. The objective of this work was to compare the growth of Prunus sellowii Koehne seedlings (pessegueirobravo), submitted to conventional fertilizations and to basalt dust as an alternative. The experiment was installed in January of 2004 in the Embrapa Florestas nursery (Colombo - PR), using medium tubes $\left(100 \mathrm{~cm}^{3}\right)$, and commercial substratum composed by Pinus husk and vermiculita. The experiment was carried out on a randomized block design, with the following treatments: without fertilization; mineral fertilization NPK; mineral fertilization NPK plus micronutrients; and basalt dust. They were evaluated the following characteristics: height, collar diameter, dry biomass (aerial and root) and leaves nutrients composition. The results had shown that seedlings growth was higher when fertilized with NPK, increased or not with micronutrients. Seedlings produced with basalt dust fertilization had not gotten similar growth to those ones without fertilization, however, in this treatment the biggest values of N, P, Ca, Mg, B, Fe and Mn in leaves had been observed.

Keywords: Pessegueiro-bravo; nursery; fertilization.
\end{abstract}

\section{INTRODUÇÃO}

O aumento dos problemas ambientais devido à grande exploração de florestas nativas realizada em amplas áreas do país, seja para formação de pasto, agricultura, serraria, seja para energia, projetos imobiliários ou para mineração, gera a crescente necessidade de recuperação de áreas e ecossistemas degradados.

Muitos fatores envolvem um programa de revegetação, e dentre os mais importantes está a produção de mudas de espécies nativas. Apesar dos esforços e dos conhecimentos já acumulados sobre essas espécies, muitos questionamentos ainda existem e pouco se sabe sobre elas.

A espécie Prunus sellowii Koehne, conhecida como pessegueiro-bravo, possui características que a tornam uma árvore promissora tanto para reflorestamentos como para recuperação de ecossistemas degradados. Essa Rosaceae é tolerante a temperaturas frias, possui madeira apreciada pelas serrarias e 
crescimento relativamente rápido, além de apresentar abundante frutificação, com ótimo poder germinativo de suas sementes (CARVALHO, 1994).

Nas últimas décadas, presenciou-se a mudança do método de produção de mudas, passando de embalagens tradicionais, como sacos plásticos, para o sistema de tubetes. Nessas embalagens, porém, devido à menor quantidade de substrato utilizado, há a obrigatoriedade de adubações, que devem ser freqüentes devido à alta lixiviação de nutrientes (GONÇALVES et al., 2000).

A maior demanda de adubações, no entanto, gera um maior custo, muitas vezes desnecessário, o que incentiva a realização de pesquisas com materiais alternativos à adubação mineral extraída quimicamente. Além disso, em virtude da própria natureza dessa adubação, existe um risco potencial ao ambiente, com Margalef (1983) afirmando que, com exceção das indústrias de limpeza, o fósforo entra como um dos principais responsáveis pela eutrofização das águas.

Há também uma grande lacuna sobre a necessidade da aplicação de micronutrientes às mudas. Apesar de inúmeros trabalhos desenvolvidos com esses elementos no Brasil, muitas dúvidas ainda surgem a respeito do efeito desses nutrientes, das fontes, bem como das doses ideais (MALAVOLTA et al., 1991).

Na tentativa de achar um fertilizante que contenha tanto macro como micronutrientes, e principalmente que seja de baixo custo, muitos materiais têm sido testados. Dentre essas alternativas está a rocha basalto, que, além das características citadas, ainda contribui para o aumento do $\mathrm{pH}$ do substrato.

No entanto, muitos anos são necessários para a natureza fragmentar as rochas, para então, em contato com a água, ácidos e calor, ocorrer a mineralização, disponibilizando os minerais para as plantas. Supõe-se neste trabalho que, ofertando ao substrato a rocha basáltica, rica em nutrientes, na forma de pó, a superfície de contato com os agentes citados será aumentada, o que irá acelerar a disponibilização dos nutrientes da rocha, funcionando como um fertilizante do solo.

O objetivo deste trabalho foi comparar o crescimento de mudas de Prunus sellowii quando utilizado pó de basalto, esse sendo confrontado com adubações convencionais, contendo ou não micronutrientes.

\section{MATERIAL E MÉTODOS}

O experimento foi instalado em janeiro de 2004, em viveiro da Embrapa Florestas, com o intuito de comparar o desenvolvimento de mudas de Prunus sellowii cultivadas com adubações convencionais, contendo ou não micronutrientes, e pó de basalto. O viveiro está localizado no município de Colombo, Paraná, situado entre e $25^{\circ} 19^{\prime} 17^{\prime}$ 'S e 4909'39'W.

Para o ensaio, foram utilizados tubetes médios, com capacidade de $100 \mathrm{~cm}^{3}$, inseridos em bandejas metálicas. O substrato utilizado foi o comercial, à base de casca de Pinus sp e vermiculita. As sementes de Prunus sellowii (pessegueiro-bravo) foram disponibilizadas pela Embrapa Florestas, procedentes de regiões próximas a Bocaiúva do Sul (PR).

Os tratamentos consistiram em quatro diferentes composições de adubações: sem adubação, adubação mineral NPK, adubação mineral NPK acrescida de micronutrientes e pó de basalto.

Para os tratamentos com adubação mineral, foi utilizada a fertilização proposta por Gonçalves et al. (2000), usada no viveiro da CESP em São Paulo. Essa adubação é aplicada tanto na base como em cobertura, e acrescida ou não de micronutrientes, dependendo do tratamento. A adubação de base por tubete foi constituída por: $0,075 \mathrm{~g}$ de sulfato de amônio, 0,166 g de superfosfato simples, 0,017 $\mathrm{g}$ de cloreto de potássio e $0,015 \mathrm{~g}$ de "fritas" - coquetel de micronutrientes. Para a adubação de cobertura, foram utilizados $0,1 \mathrm{~g}$ de sulfato de amônio e $0,025 \mathrm{~g}$ de cloreto de potássio, por muda. Essa adubação foi aplicada apenas duas vezes, nos tratamentos com adubação NPK e NPK + micronutrientes, sendo a primeira realizada 25 dias após a emergência, com $\mathrm{N}$ e $\mathrm{K}$, e a segunda passando-se mais 15 dias, somente com N.

O pó de basalto foi coletado na pedreira Ivo Kerber, situada no município de Porto União (SC). O produto principal da pedreira é a brita, e o pó de basalto é considerado um resíduo do processo de moagem. Uma vez que há poucas referências da utilização desse material na mistura em substratos, baseando-se em quantidades usadas em solos por hectare, a quantidade de pó de basalto utilizada foi de $150 \mathrm{~kg}$ por $\mathrm{m}^{3}$ de substrato, o que corresponde a $15 \mathrm{~g}$ por tubete. Como o pó de basalto é mais denso (1 kg de pó equivale a $0,660 \mathrm{ml}$ ), foi necessário adicionar 99 litros de pó de basalto por $\mathrm{m}^{3}$ de substrato. A 
análise química do pó de basalto foi realizada no laboratório do Setor de Ciências da Terra (LAMIR), da Universidade Federal do Paraná, e é apresentada na tabela 1.

Tabela 1. Análise química do pó de basalto.

Table 1. Chemical analysis of the basalt dust.

\begin{tabular}{|c|c|c|c|}
\hline \multicolumn{2}{|c|}{ Mineral } & \multirow{2}{*}{$\frac{\text { Amostra A }}{53,62}$} & \multirow{2}{*}{$\frac{\text { Amostra B }}{52,70}$} \\
\hline $\begin{array}{l}\mathrm{SiO}_{2} \\
\end{array}$ & $(\%)$ & & \\
\hline $\mathrm{Al}_{2} \mathrm{O}_{3}$ & $(\%)$ & 13,47 & 13,74 \\
\hline $\mathrm{TiO}_{2}$ & $(\%)$ & 1,19 & 1,15 \\
\hline $\mathrm{Fe}_{2} \mathrm{O}_{3}$ & $(\%)$ & 11,20 & 11,85 \\
\hline $\mathrm{CaO}$ & $(\%)$ & 9,00 & 8,96 \\
\hline $\mathrm{MgO}$ & $(\%)$ & 4,83 & 5,04 \\
\hline $\mathrm{K}_{2} \mathrm{O}$ & $(\%)$ & 1,17 & 1,11 \\
\hline $\mathrm{Na}_{2} \mathrm{O}$ & $(\%)$ & 2,95 & 3,03 \\
\hline $\mathrm{MnO}$ & $(\%)$ & 0,19 & 0,18 \\
\hline $\mathrm{P}_{2} \mathrm{O}_{5}$ & $(\%)$ & 0,20 & 0,20 \\
\hline $\mathrm{S}$ & $\left(\mathrm{mg} / \mathrm{dm}^{3}\right)$ & 139 & 135 \\
\hline $\mathrm{Zr}$ & $\left(\mathrm{mg} / \mathrm{dm}^{3}\right)$ & 1 & 1 \\
\hline $\mathrm{Nb}$ & $\left(\mathrm{mg} / \mathrm{dm}^{3}\right)$ & 31 & 31 \\
\hline $\mathrm{Rb}$ & $\left(\mathrm{mg} / \mathrm{dm}^{3}\right)$ & $<001$ & 18 \\
\hline $\mathrm{Ba}$ & $\left(\mathrm{mg} / \mathrm{dm}^{3}\right)$ & 169 & 132 \\
\hline $\mathrm{Cu}$ & $\left(\mathrm{mg} / \mathrm{dm}^{3}\right)$ & 71 & 31 \\
\hline $\mathrm{Zn}$ & $\left(\mathrm{mg} / \mathrm{dm}^{3}\right)$ & 93 & 105 \\
\hline Soma & $(\%)$ & 99,68 & 99,76 \\
\hline
\end{tabular}

O experimento foi disposto em blocos ao acaso, com seis repetições, tendo oito plantas úteis por parcela. A bordadura foi constituída de uma linha de plantas em cada extremidade do bloco.

Para cada tratamento, procedeu-se a mistura do substrato com as respectivas adubações, processo esse realizado com auxílio de uma betoneira. Após o enchimento dos tubetes com essa mistura e realização da semeadura, as bandejas foram mantidas em casa de germinação por cerca de 30 dias. Nesse período foi realizada a retirada das plântulas em excesso em cada tubete, e as mudas foram submetidas ao delineamento experimental. Depois desse período, as bandejas foram levadas para uma casa de crescimento, permanecendo nesse ambiente por 60 dias, quando, então, foram levadas a pleno sol, para rustificação.

A avaliação final ocorreu 120 dias após a emergência das sementes. As mudas foram avaliadas quanto às suas variáveis não-destrutivas (altura e diâmetro de colo\0 de todas as mudas e destrutivas (biomassa seca da parte aérea, biomassa seca de raízes e biomassa seca total) de 10 mudas por tratamento, sendo escolhidas as mais próximas da média da altura das plantas dentro de cada tratamento, independentemente das repetições. Essas últimas atividades foram realizadas no Laboratório de Ecofisiogia, localizado no Setor de Ciências Agrárias da UFPR.

Também foi realizada a análise da concentração de nutrientes foliares. Para cada tratamento foi constituída uma amostra composta, a qual foi preparada com folhas de 8 mudas por tratamento, escolhidas de acordo com a proximidade da média da altura das mudas em cada tratamento, independentemente das repetições. As análises foram realizadas pelo IAC (Instituto Agronômico de Campinas), em São Paulo.

As características físicas e químicas dos tratamentos foram obtidas através da metodologia publicada em Embrapa (1997), a qual é a mesma metodologia utilizada para solos. As análises foram realizadas no laboratório de solos, da Embrapa Florestas.

As análises estatísticas foram realizadas com o auxílio do programa STATISTICA, aplicando-se a análise de variância com o teste $\mathrm{F}$ e, em seguida, o teste de Tukey. 


\section{RESULTADOS}

Tabela 2. Análise química dos tratamentos.

Table 2. Chemical analysis of the treatments.

\begin{tabular}{|c|c|c|c|c|c|c|c|c|}
\hline \multirow{2}{*}{ Tratamentos } & \multicolumn{2}{|c|}{ pH } & $\mathrm{Ca}^{2+(2)}$ & $\mathrm{Mg}^{2+(2)}$ & $\mathbf{K}^{+(1)}$ & $\mathrm{Al}^{3+(2)}$ & $\mathbf{H}^{+}+\mathbf{A \mathbf { l } ^ { 3 + }}$ & \multirow{2}{*}{$\begin{array}{c}P^{(1)} \\
\mathrm{mg} / \mathrm{dm}^{3}\end{array}$} \\
\hline & $\mathrm{CaCl}_{2}$ & SMP & \multicolumn{5}{|c|}{$\mathrm{cmol}_{\mathrm{c}} / \mathrm{dm}^{3}$} & \\
\hline Sem adubação & 4,75 & 5,67 & 7,99 & 3,35 & 1,9 & 0,55 & 6,53 & 684,3 \\
\hline NPK & 4,74 & 5,63 & 7,66 & 4,35 & 2,72 & 1,45 & 6,82 & 818,7 \\
\hline NPK + micronutrientes & 4,76 & 5,72 & 6,23 & 7,39 & 2,32 & 1,44 & 6,25 & 818,7 \\
\hline Pó de basalto & 5,18 & 5,94 & 9,01 & 5,42 & 2,26 & 0,57 & 5,23 & 780,9 \\
\hline
\end{tabular}

(1) Extração por solução Mehlich 1; Extração por solução de $\mathrm{KCl} 1 \mathrm{~mol} / \mathrm{L}$

Tabela 3. Características físicas dos tratamentos.

Table 3. Physical characteristics of the treatments.

\begin{tabular}{lcccccc}
\hline \multirow{2}{*}{ Tratamentos } & $\begin{array}{c}\text { Matéria orgânica } \\
\mathbf{g . d m}^{-3}\end{array}$ & Areia & Areia grossa & Areia fina & Silte & Argila \\
\cline { 3 - 7 } & 595,3 & 5 & 4 & $\mathbf{g} / \mathbf{1 0 0 g}$ & & \\
\hline Sem adubação & 577,9 & 6 & 4 & 2 & 18 & 2 \\
NPK & 506,2 & 5 & 4 & 1 & 18 & 3 \\
NPK + micronutrientes & 410,0 & 16 & 12 & 4 & 22 & 4 \\
Pó de basalto & & &
\end{tabular}

Tabela 4. Altura, diâmetro de colo, biomassa seca da parte aérea, das raízes e total, de mudas de Prunus sellowii.

Table 4. Height, root collar diameter, dry biomass (aerial and radicial), of Prunus sellowii seedlings.

\begin{tabular}{|c|c|c|c|c|c|}
\hline \multirow{2}{*}{ Tratamentos } & \multirow{2}{*}{$\begin{array}{l}\text { Altura } \\
(\mathbf{c m})\end{array}$} & \multirow{2}{*}{$\begin{array}{l}\text { Diâmetro } \\
\text { (dm) }\end{array}$} & \multicolumn{3}{|c|}{ Biomassa seca (g) } \\
\hline & & & Parte aérea & Raízes & Total \\
\hline Sem adubação & $16,61 \mathrm{~b}$ & $2,539 \mathrm{~b}$ & $0,567 \mathrm{c}$ & $0,308 \mathrm{ab}$ & $0,875 \mathrm{c}$ \\
\hline NPK & $22,45 \mathrm{a}$ & $2,975 \mathrm{a}$ & $0,891 \mathrm{~b}$ & $0,349 \mathrm{a}$ & $1,240 \mathrm{~b}$ \\
\hline NPK + micronutrientes & $23,48 \mathrm{a}$ & $3,037 \mathrm{a}$ & $1,066 \mathrm{a}$ & $0,373 \mathrm{a}$ & $1,439 \mathrm{a}$ \\
\hline Pó de basalto & $17,47 \mathrm{~b}$ & $2,645 \mathrm{~b}$ & $0,586 \mathrm{c}$ & $0,268 \mathrm{~b}$ & $0,854 \mathrm{c}$ \\
\hline
\end{tabular}

Médias seguidas pela mesma letra, na vertical, não diferem entre si pelo teste de Tukey ao nível de significância de 5 \%.

Tabela 5. Índices morfológicos para mudas de Prunus sellowii, a partir de variáveis coletadas aos 120 dias após emergência.

Table 5. Morphologic index for seedlings of Prunus sellowii, from variable collected 120 days after emergency.

\begin{tabular}{lcccc}
\hline \multirow{2}{*}{ Tratamentos } & \multicolumn{4}{c}{ Índice } \\
\cline { 2 - 4 } & H/DC & BSPA/BSR & H/BSPA & IQD \\
\hline Sem adubação & 6,6 & 1,9 & 28,0 & 0,11 \\
NPK & 7,5 & 2,5 & 24,1 & 0,13 \\
NPK + micronutrientes & 7,7 & 2,9 & 21,1 & 0,13 \\
Pó de basalto & 6,6 & 2,1 & 29,4 & 0,10 \\
\hline H: altura; DC: diâmetro de colo; BSPA: biomassa seca da parte aérea; BSR: biomassa seca das rázes; IQD: índice morfológico.
\end{tabular}

H: altura; DC: diâmetro de colo; BSPA: biomassa seca da parte aérea; BSR: biomassa seca das raízes; IQD: índice morfológico.

Tabela 6. Concentração de nutrientes nas folhas de Prunus sellowii 120 dias após emergência, nas diferentes adubações.

Table 6. Concentration of nutrients in leaves of Prunus sellowii 120 days after emergency, in the different fertilizations.

\begin{tabular}{|c|c|c|c|c|c|c|c|c|c|c|}
\hline \multirow{2}{*}{ Tratamentos } & $\mathbf{N}$ & $\mathbf{P}$ & $\mathbf{K}$ & $\mathbf{C a}$ & $\mathbf{M g}$ & B & $\mathrm{Cu}$ & $\mathrm{Fe}$ & Mn & $\mathbf{Z n}$ \\
\hline & \multicolumn{5}{|c|}{$\mathrm{g} / \mathrm{kg}$} & \multicolumn{5}{|c|}{$\mathrm{mg} / \mathrm{kg}$} \\
\hline Sem adubação & 13,9 & 1,7 & 14,1 & 16,0 & 4,3 & 47,5 & 15,5 & 247,0 & 987,0 & 40,0 \\
\hline NPK & 13,9 & 2,2 & 12,0 & 18,4 & 4,4 & 45,2 & 6,2 & 331,0 & 976,0 & 41,3 \\
\hline $\mathrm{NPK}+$ micro & 13,4 & 1,4 & 10,5 & 16,1 & 4,1 & 47,1 & 7,0 & 330,0 & 991,0 & 44,1 \\
\hline Pó de basalto & 15,7 & 2,3 & 14,1 & 22,9 & 5,6 & 52,2 & 7,6 & 477,0 & 1001,0 & 42,0 \\
\hline
\end{tabular}




\section{DISCUSSÃO}

A análise química realizada nos quatro tratamentos é apresentada na tabela 2. Os dados de $\mathrm{pH}$ $\mathrm{CaCl}_{2}, \mathrm{Ca}, \mathrm{Mg}, \mathrm{K}$ e P foram comparados com escala proposta por Gonçalves e Poggiani (1996). Nessa escala, são considerados adequados os valores de $\mathrm{pH} \mathrm{CaCl}_{2}$ entre 5,5 e 6,5, Ca trocável entre 10 e 20 $\mathrm{cmol}_{\mathrm{c}} / \mathrm{dm}^{3}, \mathrm{Mg}$ total entre 5 e $10 \mathrm{cmol}_{\mathrm{c}} / \mathrm{dm}^{3}, \mathrm{~K}$ trocável entre 3,0 e $10 \mathrm{cmol}_{\mathrm{c}} / \mathrm{dm}^{3}$ e P resina entre 400 e $800 \mathrm{mg} / \mathrm{dm}^{3}$.

Pela tabela 2, os valores de $\mathrm{pH} \mathrm{CaCl}_{2}$ foram considerados baixos em todas as adubações, sendo o maior valor encontrado no tratamento com pó de basalto, que obteve $\mathrm{pH} \mathrm{CaCl}_{2}$ de 5,18 . A elevação do $\mathrm{pH}$ neste último tratamento deve-se às maiores quantidades de $\mathrm{Ca}$ e $\mathrm{Mg}$ adicionadas ao substrato pelo pó de basalto (Tabela 2). Theodoro (2000) afirma que, além de aumentar o pH, maiores quantidades de $\mathrm{Ca}$ e $\mathrm{Mg}$ contribuem para a menor perda de potássio por lixiviação. Resultados positivos utilizando pó de rocha para correção de $\mathrm{pH}$, entre eles com pó de basalto, foram encontrados por Kavaleridze (1978), Theodoro (2000) e Kiehl (2002). Já Kudla et al. (1996), os quais estudaram o uso do pó de basalto aplicado em cambissolo álico, afirmam que o uso do referido pó na correção da acidez em solos com alto poder tampão é pouco provável, tendo em vista as altas doses necessárias. Mas, comparando a análise química do pó de basalto utilizado por esse autor e o utilizado no presente trabalho, observa-se ser essa última cerca de 4 vezes mais rica em cálcio (1,75 contra 8,96\%) e conter 2 vezes mais magnésio $(2,25$ contra $4,83 \%)$.

Referente ao elemento $\mathrm{Ca}$, observa-se que nenhum tratamento proporcionou valores adequados desse elemento. Os menores valores foram encontrados quando utilizada a "adubação mineral NPK acrescida de micronutrientes" $\left(6,23 \mathrm{cmol}_{\mathrm{c}} / \mathrm{dm}^{3}\right)$, e os maiores valores no tratamento com adição de pó de basalto $\left(9,01 \mathrm{cmol}_{\mathrm{c}} / \mathrm{dm}^{3}\right)$. Segundo Martinez (2004), o cálcio tem um papel fundamental na manutenção da integridade das membranas e age como um agente cimentante nas paredes celulares. Também é importante na ativação enzimática, na regulação do movimento de água nas células e essencial para a divisão celular. Complementa o autor que, uma vez incorporado ao tecido celular, o cálcio é imóvel, necessitando ser constantemente suprido para atender o crescimento contínuo.

Em relação ao $\mathrm{Mg}$, valores adequados foram encontrados nos tratamentos com "adubação mineral NPK acrescida de micronutrientes" e com pó de basalto. Segundo Malavolta (1989), é importante que haja um bom suprimento de $\mathrm{Mg}$, pois, na planta, entre outras funções, esse elemento faz parte da formação da clorofila.

Para o elemento $\mathrm{K}$, todos os tratamentos apresentaram valores considerados médios. De acordo com a tabela 2, observa-se que a adição de pó de basalto contribuiu para o aumento de $\mathrm{K}$, sendo esses valores semelhantes ou até superiores aos tratamentos em que foram adicionadas adubações minerais. Segundo Malavolta (1989), é recomendável que haja um bom suprimento de potássio no substrato, pois esse elemento garante um crescimento vigoroso e saudável às plantas, com participação na abertura e fechamento de estômatos e, entre outras funções, na transpiração, o que induz a um melhor aproveitamento de água.

No que se refere ao elemento $\mathrm{P}$, todos os tratamentos apresentaram valores elevados desse nutriente. Contudo, em solos com elevados teores de matéria orgânica, pode ocorrer uma superestimativa dos valores de fósforo solúveis extraídos por Mehlich 1. Parte desse fósforo pode estar sofrendo o fenômeno de fixação quando em presença de hidróxido de $\mathrm{Fe}$ e $\mathrm{Al}$, em condições de baixo $\mathrm{pH}$, podendo não estar disponível para as plantas (PREVEDELLO et al., 2003). Para as mudas, a elevada concentração de $\mathrm{P}$ induz a formação de um sistema radicular mais longo e com raízes mais finas, que seriam eficientes na absorção de outros nutrientes (VILELA; ANGHINONI, 1984). Gonçalves et al. (2000) afirmam que o $\mathrm{P}$ é um elemento essencial às plantas, pois melhora todo o seu sistema radicular.

O Al pode prejudicar a solubilidade de fósforo através da formação de complexos que se precipitam como fosfato de alumínio na superfície da raiz, forma na qual a planta não o aproveita diretamente. Pode também inibir a absorção de cálcio principalmente pelo bloqueio ou competição nos sítios de troca (MARSCHNER, 1995). Considerando a importância do Ca e do P para o crescimento das plantas, a influência do $\mathrm{Al}$ inibindo a absorção de $\mathrm{Ca}$ e $\mathrm{P}$ podem ser fatores limitantes ao crescimento das plantas.

Segundo classificação de Oleynik (1987), os teores de Al no solo são considerados baixos para valores menores que $0,5 \mathrm{cmol}_{\mathrm{c}} / \mathrm{dm}^{3}$, médios para valores entre 0,5 e $1 \mathrm{cmol}_{\mathrm{c}} / \mathrm{dm}^{3}$ e altos quando os níveis de $\mathrm{Al}$ forem superiores a $1 \mathrm{cmol}_{\mathrm{c}} / \mathrm{dm}^{3}$. Pela tabela 2, os valores mais baixos de alumínio foram encontrados na testemunha, e quando adicionado pó de basalto. De acordo com Carneiro (1995), a 
presença de $\mathrm{Al}$ está diretamente relacionada ao $\mathrm{pH}$, quando, em geral, os substratos ácidos estão associados a maior quantidade de Al.

Assim, em termos químicos, observa-se que mesmo que certos nutrientes tenham sido considerados baixos em alguns tratamentos, como o $\mathrm{Ca}$, e altos em outros, como o $\mathrm{P}$, no geral, as características químicas de todos os tratamentos estão adequadas para a produção de mudas. A maior diferenciação entre os tratamentos está relacionada aos elementos $\mathrm{Al}$ e Ca, nutrientes estes que afetaram o $\mathrm{pH}$.

$\mathrm{Na}$ tabela 3 constam os resultados da análise física realizada nos tratamentos. Observou-se o aumento das quantidades de areia grossa $(0,5 \mathrm{a} 1,0 \mathrm{~mm})$ e areia fina $(0,1 \mathrm{a} 0,25 \mathrm{~mm})$ quando adicionado pó de basalto ao substrato, contendo valores até três vezes maiores que nos demais tratamentos. Também as quantidades de silte $(0,002$ a $0,05 \mathrm{~mm})$ e argila $(<0,002)$ foram maiores quando adicionado pó de basalto. Neste tratamento, portanto, concentraram-se maiores quantidades de partículas menores que 1,0 $\mathrm{mm}$, as quais, segundo Carneiro (1995), implicam a formação de poros pequenos, resultando numa movimentação do ar lenta e decréscimo na capacidade de infiltração de água e transporte de nutrientes. Essa velocidade reduzida de infiltração da água pode ter resultado em menor aproveitamento das regas, sendo sugerido para esse tratamento um manejo da irrigação, com um maior número de regas por dia e em menores intensidades.

Os dados de crescimento e biomassa seca das mudas de Prunus sellowii são apresentados na tabela 4.

Para a variável altura $(\mathrm{H})$, o maior desenvolvimento das mudas foi observado no tratamento com "adubação mineral NPK acrescida de micronutrientes", que obteve a média de 23,48 cm, seguido das mudas produzidas apenas com "adubação mineral NPK", com média de $22,45 \mathrm{~cm}$. Esses diferiram estatisticamente da testemunha, que apresentou $16,61 \mathrm{~cm}$, e do tratamento onde foi testado o pó de basalto, o qual obteve $17,41 \mathrm{~cm}$ de média em altura das mudas.

Na variável diâmetro de colo (DC), observou-se a mesma tendência estatística observada para a variável altura, com a "adubação mineral NPK acrescida de micronutrientes" e a "adubação mineral NPK" sendo significativamente superiores às demais, e a adubação com pó de basalto obtendo valores absolutos de diâmetro de colo maiores que a testemunha.

Referente aos dados de biomassa seca da parte aérea (BSPA), biomassa seca de raízes (BSR) e biomassa seca total (BST), observa-se que a "adubação mineral NPK acrescida de micronutrientes" proporcionou resultados maiores que as demais adubações. Esse fato evidencia a importância da aplicação de micronutrientes na adubação, quando produzidas mudas de pessegueiro-bravo. Wright et al. (1999), em estudo de crescimento de nove espécies arbóreas, utilizando ou não calcário e micronutrientes em dois substratos de casca de Pinus taeda, com diferentes valores de $\mathrm{pH}$, observaram uma maior BSPA e altura das plantas em todas as espécies em que foram utilizados micronutrientes.

Pelos resultados da tabela 4, observa-se que a aplicação do pó de basalto ao substrato, mesmo possuindo características químicas adequadas ao crescimento de mudas (Tabela 2), não proporcionou os melhores crescimentos das mudas de Prunus sellowii. $\mathrm{O}$ fator que pode ter prejudicado o substrato com pó de basalto é a condição física que, pela tabela 3, possui as maiores quantidades de partículas minerais pequenas, prejudicando a aeração do substrato. Supõe-se que, com aplicação de menores quantidades de pó de basalto no substrato, haveria uma menor influência dele na porosidade, possibilitando às mudas aproveitarem adequadamente os nutrientes desse pó. Kiehl (2002) recomenda utilizar de 50 a 100 toneladas de pó de basalto por hectare, em solos empobrecidos, para torná-los férteis novamente. O autor, que realizou pesquisas na Escola Superior da Agricultura Luiz de Queiroz (Esalq), USP de Piracicaba (SP), afirma que a utilização do pó de basalto para a correção dos solos trouxe resultados positivos, tornando-se uma alternativa bastante favorável aos agricultores.

$\mathrm{Na}$ tabela 5 constam os índices morfológicos (IQD) para mudas de Prunus sellowii. Observa-se que os quatro índices possuíram a mesma tendência, com os tratamentos que receberam "adubação mineral NPK" e "adubação mineral NPK acrescida de micronutrientes" apresentando as menores relações H/BSPA, e as maiores relações H/DC, BSPA/BSR e IQD. Ou seja, mudas submetidas a essas adubações apresentaram médias bem maiores referentes à parte aérea da muda. Basta saber se os sistemas radiculares dessas mudas, em campo, irão fornecer água e nutrientes suficientes a essa maior biomassa da parte aérea.

Analisando as concentrações de nutrientes encontradas nas folhas de mudas de Prunus sellowii nas diferentes adubações (Tabela 6), observa-se que os maiores valores de $\mathrm{N}, \mathrm{P}, \mathrm{K}, \mathrm{Ca}, \mathrm{Mg}, \mathrm{B}, \mathrm{Fe}$ e $\mathrm{Mn}$ foram obtidos nas mudas produzidas na adubação com pó de basalto. Já para as mudas produzidas nos 
tratamentos com "adubação mineral NPK" e "adubação mineral NPK acrescida de micronutrientes", as quais obtiveram maior biomassa da parte aérea, a menor concentração de nutrientes foliares pode denotar um efeito de diluição dos mesmos, visto que as mudas produzidas com pó de basalto obtiveram menor crescimento foliar. No entanto, mudas produzidas nesse último tratamento apresentaram crescimento biométrico maior que mudas produzidas no tratamento sem adubação, e mesmo assim as quantidades de nutrientes foliares foram maiores no tratamento com pó de basalto, exceto para o elemento $\mathrm{Cu}$.

É interessante observar que, quando adicionado pó de basalto, além de maiores concentrações de $\mathrm{Ca}$ e $\mathrm{Mg}$, o que já era esperado, também houve melhor absorção de N e P pelas folhas de Prunus sellowii. Deve-se lembrar que tanto a testemunha como os tratamentos com pó de basalto não receberam adubação nitrogenada durante o experimento. $\mathrm{O}$ fator que pode ter favorecido esse quadro é justamente as maiores concentrações de cálcio proporcionadas pelo pó de basalto. Segundo Faquin (1994), o Ca está envolvido no metabolismo do N, e Deichmann (1967) afirma que o Ca aumenta a disponibilidade de P.

Para os tratamentos com "adubação mineral NPK acrescida de micronutrientes", nos quais foi adicionado um coquetel de micronutrientes ("fritas") ao substrato, a presença de maiores concentrações de micronutrientes já era esperada. No entanto, ressalta-se o pó de basalto como um potencial fornecedor de microelementos, entre eles $\mathrm{B}, \mathrm{Cu}, \mathrm{Fe}$ e $\mathrm{Mn}$. Esses micronutrientes foram encontrados em maiores concentrações nas folhas de pessegueiro-bravo ao se adicionar pó de basalto, em relação a quando aplicado "fritas".

\section{CONCLUSÕES}

Mudas de Prunus sellowii obtiveram maiores variáveis biométricas quando adubadas com NPK acrescido de micronutrientes, demonstrando ser a espécie exigente em adubações mais completas.

A adubação com pó de basalto não permitiu um crescimento das mudas similar a quando aplicadas adubações com NPK acrescidas ou não com micronutrientes, porém foram encontrados os maiores valores de N, P, K, Ca, Mg, B, Fe e Mn nas folhas de mudas de Prunus sellowii.

A utilização de pó de basalto na mistura proporcionou boas qualidades químicas ao substrato, no entanto, a quantidade utilizada deve ser ajustada, em vista dele ter modificado as características físicas ao fornecer maiores quantidades de partículas minerais finas, interferindo na porosidade e conseqüente aeração e infiltração da água, o que pode ter prejudicado o crescimento das mudas.

\section{AGRADECIMENTOS}

Aos técnicos do viveiro da Embrapa Florestas, pelos serviços prestados, e ao pesquisador Edilson Batista de Oliveira, pelo auxílio na estatística.

\section{REFERÊNCIAS}

CARNEIRO, J. G. A. Produção e controle de qualidade de mudas florestais. Curitiba: FUPEF, 1995. 451 p.

CARVALHO, P. E. R. Espécies florestais brasileiras: recomendações silviculturais, potencialidades e uso da madeira. Colombo: Embrapa-Florestas, 1994. 640 p.

DEICHMANN, V. V. Noções sobre sementes e viveiros florestais. Curitiba: Escola de Florestas, UFPR, 1967. $196 \mathrm{p}$.

EMBRAPA. Manual de métodos de análise de solo. Rio de Janeiro, Centro Nacional de Pesquisa de Solo, 1997. 212 p.

FAQUIN, V. Nutrição Mineral de Plantas. Lavras: UFLA/FAEPE, 1994. v. 1, 227 p.

GONÇAlVES, J. L. de M.; SANTARELli, E. G.; MORAES NETO, S. P. de; MANARA, M. P. Produção de mudas de espécies nativas: substrato, nutrição, sombreamento e fertilização. In: GONÇALVES, J. L. M.; BENEDETTI, V. Nutrição e fertilização florestal. Piracicaba: IPEF, 2000. p. 310-350.

GONÇALVES, J. L. M.; POGGIANI, F. Substrato para produção de mudas florestais. In: SOLOSUELO- CONGRESSO LATINO AMERICANO DE CIÊNCIA DO SOLO, 13, 1996. Águas de Lindóia- 
SP. Relação de trabalhos. Águas de Lindóia: SLCS/SBCS/ESALQ/USP/CEA-ESALQ/USP/SBM, 1996. 1 CD-ROM.

KAVALERIDZE, W. C. Nossos solos: formação, vida dinâmica, tratamento e conservação. 2. ed. Curitiba, 1978. $168 \mathrm{p}$.

KIEHL, E. J. Manual de Compostagem: maturação e qualidade do composto; 3. ed., Piracicaba: E. J. Kiehl, 2002. $171 \mathrm{p}$.

KUDLA, A. P.; MOTTA, A. C. V.; KUDLA, M. E. Efeito do uso do pó de basalto aplicado em um cambissolo álico sobre o solo e crescimento do trigo. Revista do Setor de Ciências Agrárias, Curitiba, v. 15 , n. 2, p. 187-195, 1996.

MALAVOLTA, E. ABC da Adubação. 5. ed. São Paulo: Agronômica Ceres, 1989. 292 p.

MALAVOLTA, E.; BOARETTO, A. E.; PAULINO, V. T. Micronutrientes uma visão geral. In: SIMPÓSIO SOBRE MICRONUTRIENTES NA AGRICULTURA, 1., Jaboticabal, 1988. Anais... Piracicaba: Potafos/ CNPq, 1991. p. 734.

MARGALEF, R. Limnologia. Barcelona: Omega, 1983. 1010 p.

MARSCHNER, H. Mineral nutrition of higher plants. San Diego: Academic,1995. 889 p.

MARTINEZ, H. E. P. Distúrbios nutricionais em hortaliças cultivadas em substratos com baixa atividade quimica. In: BARBOSA, J. G., et al. Nutrição e adubação de plantas cultivadas em substrato: palestras realizadas e resumos apresentados no IV ENSUB - Encontro Nacional sobre substrato para plantas, 4., Viçosa, MG: [s.n.], 2004. p. 129-157.

OLEYNIK, J. Análise de solo: tabelas para transformação de resultados analíticos e interpretação de resultados. Curitiba: Acarpa, 1987. 28 p.

PREVEDELLO, B. M. S.; KRIEGER, K. I.; MOTTA, A. C. V. Considerações sobre interpretação de análise de solos (com exemplos). In: LIMA, M.R. (Org.). Manual de diagnóstico da fertilidade e manejo dos solos agrícolas. Curitiba: Departamento de solos e engenharia agrícola-UFPR, 2003. p. 123141 .

THEODORO, S. de C. H. A fertilização da terra pela terra: uma alternativa para a sustentabilidade do pequeno produtor rural. $225 \mathrm{f}$. Tese (Doutorado em Geologia) - Universidade de Brasília, Brasília, DF, 2000.

VILELA, L.; ANGHINONI, I. Morfologia do sistema radicular e cinética de absorção de fósforo em cultivares de soja afetados pela interação alumínio-fósforo. Revista Brasileira de Ciência do Solo, Campinas, v. 8, n. 1, p. 91-96, 1984.

WRIGHT, A. N.; NIEMIERA, A. X.; HARRIS, J. R.; WRIGHT, R. D. Preplant lime and micronutrient amendments to pine bark affect growth of seedlings of nine container-grown tree species. HortScience, Alexandria, v. 34, n. 4, p. 669-673, 1999. 